\title{
Prevalence of type-specific HPV among female university students from northern Brazil
}

\author{
Rodrigo Covre Vieira ${ }^{*}$, Jeniffer do Socorro Valente Monteiro ${ }^{2}$, Estéfane Primo Manso², \\ Maria Renata Mendonça dos Santos ${ }^{3}$, Mihoko Yamamoto Tsutsumi ${ }^{4}$, Edna Aoba Yassui Ishikawa ${ }^{1}$, \\ Stephen Francis Ferrari ${ }^{5}$, Karla Valéria Batista Lima ${ }^{6}$ and Maísa Silva de Sousa ${ }^{1}$
}

\begin{abstract}
Background: Human papillomavirus (HPV) infection is associated with cervical cancer, the most frequent cancer in women from northern Brazil. Assessment of the short-term impact of HPV vaccination depends on the availability of data on the prevalence of type-specific HPV in young women in the pre-immunization period, although these data are currently unavailable for the study region. The aim of this study was to estimate the distribution of all mucosal HPV genotypes, including low- and high-risk HPV types, in unvaccinated college students from northern Brazil.

Findings: Specimens were collected from 265 university students during routine cervical cancer screening. The HPV DNA was assessed by Polymerase Chain Reaction and positive samples were genotyped by Restriction Fragment Length Polymorphism. Most students (85.7\%) had normal cytological results. The prevalence of HPV was $25.3 \%$ (67/265), with a high frequency of multiple infections and non-vaccine high-risk HPV genotypes. The most prevalent type was HPV-61 (5.3\%), followed by types 82, 16, 59, and 6. Multiple infections were associated with high-risk and possibly high-risk HPVs.

Conclusions: We demonstrated a high prevalence of HPV infection in university students from northern Brazil. Vaccine high-risk types were relatively rare, emphasizing the predominance of carcinogenic genotypes that are not prevented by the currently available vaccines. Our study highlights the need to reinforce cytological screening in women from northern Brazil, and promote the early diagnosis and treatment of the precancerous lesions associated with cervical cancer.
\end{abstract}

Keywords: Human papillomavirus, Prevalence, HPV vaccine impact, Genotype distribution

\section{Findings}

\section{Introduction}

Human papillomavirus (HPV) is a non-enveloped doublestranded DNA virus of the family Papillomaviridae [1]. Persistent infections with high-risk HPVs (hrHPV) can progress to Cervical Cancer (CC) [2]. While this cancer is the third most common in women both worldwide [3], and in Brazil in general, it is the most frequent in women from northern Brazil. It thus constitutes a serious public health problem in this region [4].

Prophylactic HPV vaccination in Brazil began in March 2014 as part of national immunization program for girls

\footnotetext{
* Correspondence: rodrigobjt@hotmail.com

${ }^{1}$ Laboratory of Molecular and Cellular Biology, Center for Tropical Medicine

(1st Floor), Federal University of Pará, Belém, Pará, Brazil

Full list of author information is available at the end of the article
}

aged 9 to 13 years old. The quadrivalent vaccine (Gardasil) adopted for this program provides protection from the two hrHPVs found in $70 \%$ of all cases of CC (HPV-16 and HPV-18), as well as protection from two low-risk HPVs (lrHPV) that cause about $90 \%$ of cases of genital warts (HPV-6 and HPV-11) [5].

The effects of HPV vaccination on CC rates will only be apparent after a number of years. A short-term assessment of the impact of the vaccination program can be provided by the evaluation of the prevalence of typespecific HPV in vaccinated young women [6, 7], although the systematic evaluation of any change in the distribution of the virus will depend on the availability of data from the pre-immunization period, which are currently unavailable for the study region.

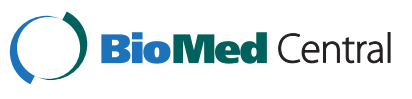

(c) 2015 Vieira et al. This is an Open Access article distributed under the terms of the Creative Commons Attribution License (http://creativecommons.org/licenses/by/4.0), which permits unrestricted use, distribution, and reproduction in any medium, provided the original work is properly credited. The Creative Commons Public Domain Dedication waiver (http:// creativecommons.org/publicdomain/zero/1.0/) applies to the data made available in this article, unless otherwise stated. 
The present study aims to estimate the prevalence of all mucosal HPV types, including low-risk and hrHPV types, in female university students from northern Brazil prior to the introduction of HPV vaccination.

\section{Methods}

Between October 2012 and October 2013, cervical specimens were collected from female students as part of a routine $\mathrm{CC}$ screening program based on the Pap test and analyzed at the Cytology Laboratory of the Federal University of Pará (UFPA) in Belém, Brazil. After sample collection, the endocervical brush was washed into microtubes containing $0.5 \mathrm{~mL}$ of saline that were stored at $-20{ }^{\circ} \mathrm{C}$ until the molecular analysis. At the UFPA Molecular and Cellular Biology Laboratory, the viral DNA was extracted using the standard phenol-chloroform protocol and purified by ethanol precipitation [8]. Polymerase Chain Reaction (PCR) of the human $\beta$-globin gene was conducted prior to HPV detection to confirm the suitability of the samples [9].

The HPV PCR was conducted using degenerate MY09/ MY11 primers [10] and the HPV-positive cases were typed by Restriction Fragment Length Polymorphisms (RFLP) [11], which permit the identification of the 13 hrHPVs classified by the International Agency for Research on Cancer (IARC) as being at least "probably carcinogenic to humans" (HPV 16, 18, 31, 33, 35, 39, 45, 51, $52,56,58,59$ and 68 ), twelve possibly high-risk types (HPV 26, 30, 34, 53, 66, 67, 69,70, 73, 82, 85 and 97) and other genotypes classified as lrHPVs, including HPV-6 and HPV-11 [12]. The conventional cytology results were classified according to the Bethesda's terminology [13].

This study was approved by the Human Research Ethics Committee of the UFPA Center for Tropical Medicine $\left(\mathrm{n}^{\circ}\right.$ 167.270/2012), in accordance with all the directives and norms regulating research involving humans in Resolution $n^{\circ}$. 446/2012 of the Brazilian National Health Council. Informed consent was obtained from all participants.

\section{Results}

A total of 265 university students were included in the study (mean age $25 \pm 5.7$ years; range: from 18 to 55 years). The mean age of first intercourse was $18 \pm 2.9$ years, and the mean age at menarche was $12 \pm 1.5$ years. Most $(75 \%)$ of the individuals had had two or more sexual partners during their lifetime, $90 \%$ were single, $99 \%$ did not smoke, and more than half (59\%) used condoms during sexual relations. Just under half (49 \%) of the participants were having Pap screening for the first time.

No evidence was found of invasive carcinoma in any of the samples.

High-grade Squamous Intraepithelial Lesions (HSIL) were found in six samples (2.3\%), and Low-grade lesions (LSIL) in 17 (6.4\%), Atypical Squamous Cells of
Undetermined Significance (ASCUS) in 14 (5.3\%), and Atypical Squamous Cells, cannot exclude HSIL (ASCH) in one $(0.4 \%)$. The other 227 samples analyzed in this study presented normal cytology (85.7 \%).

The DNA of HPV was detected in cervical specimens of 67 women, with an overall prevalence of $25.3 \%(67 / 265)$. The prevalence of HPV among women with normal cytology was $23.4 \%$ (53/227), increasing to $36.9 \%(14 / 38)$ in women with abnormal cytology of any kind. There was no statistical association between the occurrence of HPV infections and abnormal cytology ( $p>0.05)$.

Twenty HPV types were detected (Fig. 1), including seven hrHPVs $(16,18,45,52,58,59$ and 68), five possibly hrHPVs (26, 53, 66, 70 and 82), and eight lrHPVs $(6,54,61,74,81,83,90$ and 106), with no genotype being determined in six samples. The most frequent genotype was HPV-61, followed by HPV-82, HPV-16, HPV-59 and HPV-6. Of the high-risk infections, HPV-16 and HPV-59 were the most prevalent genotypes, which were each detected in seven samples (2.7\%), whereas HPV-61 was the low-risk genotype most often detected (5.3\%). While HPV-6 was identified in six samples (2.3\%), HPV-11 was not detected at all in the present study. The possibly hrHPVs were observed in 11 samples, of which HPV-82 was the most prevalent genotype (3\%).

Single infections were detected in $59 \%(36 / 61)$ of the genotyped samples, while multiple genotypes were identified in $41 \%(25 / 61)$. The five most common genotypes in multiple infections were HPV-82, HPV-16, HPV-18, HPV68 and HPV-6. High-risk HPVs and possibly hrHPVs were found more frequently in multiple infections than in single infections. Low-risk genotypes were associated with single infections (Table 1).

High-risk HPV infections were identified in 26 samples $(9.8 \%)$, of which 12 presented vaccine HPV-16 or HPV-18 (4.5\%). Overall, non-vaccine hrHPVs were found in approximately $77 \%$ of the high-risk cases $(20 / 26)$. Fourteen individuals were infected exclusively by non-vaccine hrHPVs and six were co-infected with HPV-16 or HPV18. Infections associated exclusively with vaccine hrHPVs were recorded in only six cases.

\section{Discussion}

Our study demonstrated a HPV prevalence of $25.3 \%$ among unimmunized university students from northern Brazil. In the Pap test, $85.7 \%$ of the students screened had normal cytology. Despite the high prevalence of HPV infection, a low prevalence of vaccine hrHPVs was detected (4.5\%), with non-vaccine types predominating in high-risk cases. In addition, some HPVs that present vaccine cross-protection in vaccine trials due to their genetic similarities with HPV-16 and HPV-18, mainly HPV-31, 33, 45, 52 and 58 [14, 15], were also rare in our study, as were the vaccine lrHPVs (HPV-6 and HPV-11). 


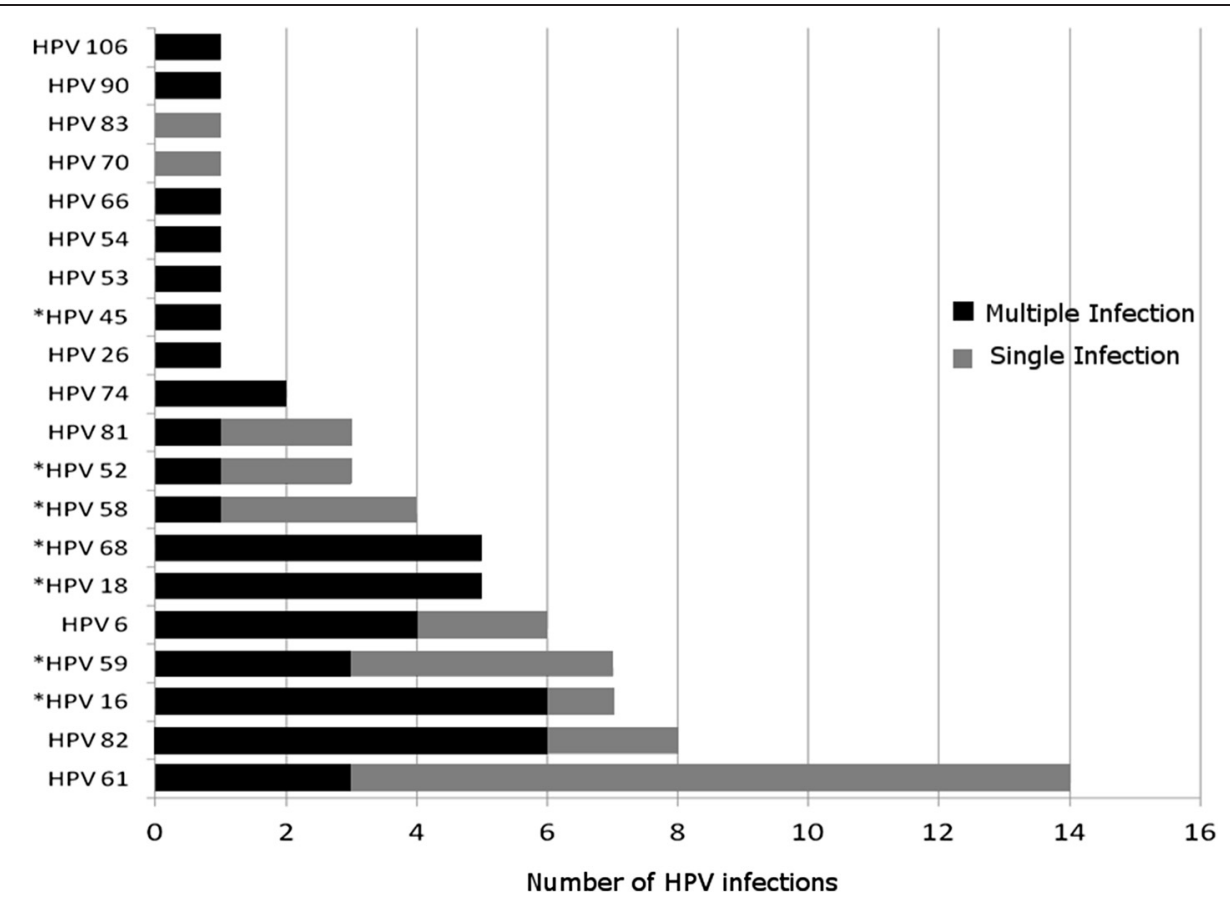

Fig. 1 Absolute frequency of the 20 types of HPV detected in single and multiple infections (HPV: human papillomavirus; *oncogenic types)

The prevalence of HPVs recorded in the present study was much higher than that found by Bruni et al. [16] in a meta-analysis of the worldwide data, in which the overall HPV prevalence among women with normal cytology was $11.7 \%$. In Brazil, there is considerable variation in the prevalence of HPVs and the distribution of genotypes. The prevalence recorded here was much higher than that found in previous studies in southern (6.7 \%) [17] and southeastern Brazil (11 \%) [18], but lower than that described in a previous study in northern Brazil (29.4 \%) [19]. However, all these previous studies recorded HPV-16 as the most prevalent genotype, whereas in the present study, HPV-61 and HPV-82 were the most common, although HPV-16 was the most frequent hrHPV genotype, together with HPV-59.

The effectiveness of HPV vaccines for the reduction of the incidence of $\mathrm{CC}$ will depend on a number of factors, including vaccine coverage, the efficacy achieved with one, two or three doses of the vaccine, the degree of cross-protection provided against HPV types not included in the vaccines, and the prevalence of the genotypes for which the vaccines do provide protection [15]. Our study demonstrated a high prevalence of hrHPVs that are not prevented by vaccination. Despite the good vaccination coverage achieved during the first vaccination campaign, coverage for the second dose fell to $42.2 \%$ in Brazil as a whole, and only $18.1 \%$ in Pará, where our study was conducted [20].

Multiple infections were very common in our study, and typically involved hrHPVs and possibly hrHPV genotypes. An association may exist between some pairs of high-risk genotypes, which may determine their role in multiple infections [21]. A better understanding of the mechanisms of synergism or antagonism involved in high-risk infections will be important for the prediction of the impact of vaccination programs on the distribution and replacement of HPV genotypes [22]. The high frequency of infections by possibly hrHPVs, especially HPV-82 (the second most prevalent in our study), also emphasizes the need for stricter epidemiological surveillance of these types in northern Brazil, in addition to those already classified as hrHPVs.

Table 1 Distribution of HPV types according to the mode of infection (single or multiple)

\begin{tabular}{lccccc}
\hline Type of HPV & Number of samples & Single infection (\%) & Multiple Infection ${ }^{\mathrm{a}}(\%)$ & $\mathrm{p}^{*}$ & Odds Ratio $(95 \% \mathrm{Cl})^{\mathrm{b}}$ \\
\hline hrHPV & 26 & $9(34.6)$ & $17(65.4)$ & 0.0021 & $6.38(2.06-19.72)$ \\
possibly hrHPV & 11 & $3(27.3)$ & $8(72.7)$ & 0.0428 & $5.18(1.21-22)$ \\
IrHPV & 33 & $24(72.7)$ & $9(27.3)$ & 0.0355 & $0.28(0.1-0.82)$ \\
\hline
\end{tabular}

*Values of less than 0.05 were considered significant

${ }^{\mathrm{a}} 2$ or 3 different genotypes

${ }^{\mathrm{b}} \mathrm{Cl}=$ Confidence Interval 
The small sample size and the convenience sampling procedure adopted in our study represent two potential limitations, although these considerations are outweighed by the need for data on the prevalence and distribution of HPV genotypes from this poorly-studied region, which are essential for epidemiological monitoring and in particular, the short-term evaluation of the effectiveness of the vaccination program established recently in Brazil. The inclusion of subjects with abnormal cytology may also have been a limiting factor. Nevertheless, the future evaluation of the vaccine effectiveness requires pre-vaccination data both in women with normal and abnormal cytology results. Moreover, our study sample was not obtained from a referral centre or colposcopy clinic and only a small proportion of the participants had abnormal cytology, which did not consistently affect the overall HPV prevalence.

\section{Conclusions}

Despite the high prevalence of HPV (25.3\%) in the study group from northern Brazil, the vaccine hrHPVs were relatively rare. In other words, there was a predominance of carcinogenic genotypes against which the vaccine does not confer immunity. This highlights the need to reinforce cytological screening as a basic tool for the early diagnosis and treatment of precancerous CC lesions in northern Brazil, where CC incidence and mortality rates are unusually high.

\footnotetext{
Abbreviations

HPV: Human papillomavirus; hrHPV: High-risk HPV; PCR: Polymerase chain reaction; RFLP: Restriction fragment length polymorphism; IrHPV: Low-risk HPV; OR: Odds ratio; 95 \% Cl: 95 \% confidence interval; LSIL: Low-grade Squamous Intraepithelial Lesion; HSIL: High-grade Squamous Intraepithelial Lesion; ASCUS: Atypical Squamous Cells of Undetermined Significance; ASCH: Atypical Squamous Cells, cannot exclude HSIL.
}

\section{Competing interests}

The authors declare that they have no competing interests.

\begin{abstract}
Authors' contributions
$\mathrm{RV}$ drafted the manuscript, participated in the analysis and interpretation of the data and conducted statistical analysis. JM and EM participated in acquisition of data, the molecular analysis, and helped in the design of the study. MRS and MT collected the biological samples, participated in the acquisition of data and helped to draft the manuscript. El and SFF revised the final version of the manuscript and provided suggestions. $\mathrm{KL}$ and MS conceived the study and revised critically the intellectual content of the manuscript. All the authors read and approved the final draft of the manuscript.
\end{abstract}

\section{Acknowledgements}

Vice Rectory for Academic Extension (PROEX), Federal University of Pará (UFPA).

\footnotetext{
Author details

'Laboratory of Molecular and Cellular Biology, Center for Tropical Medicine (1st Floor), Federal University of Pará, Belém, Pará, Brazil. ${ }^{2}$ College of Pharmaceutical Sciences, Federal University of Pará, Belém, Pará, Brazil. ${ }^{3}$ Postgraduate Program in Clinical Analysis, Federal University of Pará, Belém, Pará, Brazil. ${ }^{4}$ Cytology Laboratory, Institute of Biological Sciences, Federal University of Pará, Belém, Pará, Brazil. ${ }^{5}$ Department of Ecology, Universidade Federal de Sergipe, Sergipe, Brazil. 'Bacteriology Section, Evandro Chagas Institute, Ananindeua, Pará, Brazil.
}

Received: 12 December 2014 Accepted: 2 July 2015

Published online: 22 July 2015

\section{References}

1. Bernard HU, Burk RD, Chen Z, Van Doorslaer K, Zur Hausen H, de Villiers EM. Classification of Papillomaviruses (PVs) based on 189 pv types and proposal of taxonomic amendments. Virology. 2010;401(1):70-9.

2. Muñoz N, Bosch FX, de Sanjosé S, Herrero R, Castellsagué X, Shah KV, et al. Epidemiologic Classification of Human Papillomavirus Types Associated with Cervical Cancer. N Engl J Med. 2003;348:518-27.

3. International Agency for Research of Cancer - IARC. GLOBOCAN. Estimated cancer Incidence, Mortality.and Prevalence in World in 2012. Lyon: IARC, 2015; 2012. Available from: http://globocan.iarc.fr/Default.aspx.

4. Instituto nacional de câncer (Brasil). Estimativa 2014. Incidência do Câncer no Brasil. Rio de Janeiro: Instituto nacional de câncer (Brasil); 2014.

5. Bosch FX, Lorincz A, Munoz N, Meijer CJL, Shah KV. The causal relation between human papillomavirus and cervical cancer. J Clin Pathol. 2002;55(4):244-65

6. Deleré $Y$, Remschmidt $C$, Leuschner J, Schuster $M$, Fesenfeld $M$, Schneider A, et al. Human Papillomavirus prevalence and probable first effects of vaccination in 20 to 25 year-old women in Germany: a population-based cross-sectional study via home-based self-sampling. BMC Infect Dis. 2014;19:14:87.

7. Mesher D, Soldan K, Howell-Jones R, Panwar K, Manyenga P, Jit M, et al. Reduction in HPV 16/18 prevalence in sexually active young women following the introduction of HPV immunisation in England. Vaccine. 2014;32(1):26-32.

8. EMBRAPA. Fundamentos teórico-práticos e protocolos de extração e de amplificação de DNA por meio da técnica de reação em cadeia da polimerase. [http://www.alice.cnptia.embrapa.br/bitstream/doc/48295/1/ LivroProtMolecular.pdf]

9. Rabelo-Santos SH, Levi JE, Derchain SF, Sarian LO, Zeferino LC, Messias S, et al. DNA recovery from Hybrid Capture II samples stored in specimen transport medium with denaturing reagent, for the detection of human papillomavirus by PCR. J Virol Methods. 2005;126(1-2):197-201.

10. Manos MM, Ting Y, Wright DK, Lewis AJ, Broker TR, Wolinsky SM, et al. The use of polymerase chain reaction amplification for the detection of genital human papillomaviruses. Cancer Cells. 1989;7:209-14.

11. Nobre RJ, de Almeida LP, Martins TC. Complete genotyping of mucosal human papillomavirus using a restriction fragment length polymorphism analysis and an original typing algorithm. J Clinic Virol. 2008;42(1):13-21.

12. Bouvard V, Baan R, Straif K, Grosse Y, Secretan B, El Ghissassi F, et al. A review of human carcinogens - Part B: biological agents. Lancet Oncol. 2009;10:321-2.

13. Solomon D, Davey D, Kurman R, Moriarty A, O'Connor D, Prey M, et al. The 2001 Bethesda System: terminology for reporting results of cervical cytology. JAMA. 2002;287(16):2114-9.

14. Brown DR, Kjaer SK, Sigurdsson K, Iversen OE, Hernandez-Avila M, Wheeler $\mathrm{CM}$, et al. The impact of quadrivalent human papillomavirus (HPV; types 6, 11,16 , and 18) L1 virus-like particle vaccine on infection and disease due to oncogenic nonvaccine HPV types in generally HPV-naive women aged 16-26 years. J Infect Dis. 2009;199(7):926-35.

15. Wheeler CM, Kjaer SK, Sigurdsson K, Iversen OE, Hernandez-Avila M, Perez G, et al. The impact of quadrivalent human papillomavirus (HPV; types 6, 11, 16 , and 18) L1 virus-like particle vaccine on infection and disease due to oncogenic nonvaccine HPV types in sexually active women aged 16-26 years. J Infect Dis. 2009;199(7):936-44.

16. Bruni L, Diaz M, Castellsagué X, Ferrer E, Bosch FX, de Sanjosé S. Cervical Human Papillomavirus Prevalence in 5 Continents: Meta-Analysis of 1 Million Women with Normal Cytological Findings. J Infect Dis. 2010;202(12):1789-99.

17. da Silva MC, Martins HP, de Souza IL, Tognim MC, Svidzinski TI, Teixeira JJ, et al. Prevalence of HPV infection and genotypes in women with normal cervical cytology in the state of Paraná, Brazil. Arch Gynecol Obstet. 2012;286(4):1015-22.

18. Miranda PM, Pitol BC, Moran MS, Silva NN, Felix PM, Lima-Filho JL, et al. Human papillomavirus infection in Brazilian women with normal cervical cytology. Genet Mol Res. 2012;11(2):1752-61.

19. Tamegão-Lopes BP, Sousa-Júnior EC, Passetti F, Ferreira CG, de Mello WA, Duarte Silvestre RV. Prevalence of human papillomavirus infection and phylogenetic analysis of HPV-16 E6 variants among infected women from Northern Brazil. Infect Agent Cancer. 2014;9:25. 
20. Ministério da Saúde. [http://portalsaude.saude.gov.br/]

21. Goldman B, Rebolj M, Rygaard C, Preisler S, Ejegod DM, Lynge E, et al. Patterns of cervical coinfection with multiple human papilloma virus types in a screening population in Denmark. Vaccine. 2013;31(12):1604-9.

22. Pons-Salort M, Letort V, Favre M, Heard I, Dervaux B, Opatowski L, et al. Exploring individual HPV coinfections is essential to predict HPV-vaccination impact on genotype distribution: a model-based approach. Vaccine. 2013;31(8):1238-45.

Submit your next manuscript to BioMed Central and take full advantage of:

- Convenient online submission

- Thorough peer review

- No space constraints or color figure charges

- Immediate publication on acceptance

- Inclusion in PubMed, CAS, Scopus and Google Scholar

- Research which is freely available for redistribution 